\title{
Letrônica
}

\section{Histórias de afetos: migração e a busca por identidade em Azul Corvo}

Histories of affection: migration and the search for identity in Azul Corvo

Licenciada em Letras (UFRGS) e Especialista em Literatura Brasileira (PUCRS). Mestranda do Programa de Pós-Graduação em Letras da Universidade Federal do Rio Grande do Sul, na área de concentraçäo de Estudos de Literatura. Bolsista

(7) http://orcid.org/0000-0001-5041-5667

E-mail: priscilapedo@gmail.com
Priscila Martini Pedó ${ }^{1}$

Programa de Pós-Graduação em Letras, Instituto de Letras, Universidade Federal do Rio Grande do Sul. Porto Alegre, RS, Brasil

RESUMO: 0 objeto de estudo deste trabalho é o romance Azul Corvo, de Adriana Lisboa (2010). Nosso olhar dirige-se à Evangelina, personagem que, aos vinte e dois anos, recupera as experiências vividas nove anos atrás, quando migra para os Estados Unidos em busca do pai biológico após o falecimento da mãe. Partindo do pressuposto de que a busca da personagem pela figura paterna é uma busca por identidade e por pertencimento, analisamos como se deu esse processo em um contexto migratório. Para tanto, reconstruímos as histórias de três personagens - Evangelina, Fernando e Suzana -, buscando destacar os pontos de intersecção e apontando elementos de complementariedade entre elas.

Palavras-chave: Identidade; Migração; Memória; Ditadura.

ABSTRACT: This article has as its object of study the novel Azul Corvo, from the writer Adriana Lisboa (2010). Our focus is towards Evangelina, character that, at the age of twenty-two, recovers the experiences that she lived nine years ago when she migrated to the United States searching for her biological father, after her mother's death. Based on the assumption that the character's search for a fatherly figure is a way to seek identity and belonging, we analyze how this process happened in a migratory context. Therefore, we rebuild the stories of three characters - Evangelina, Fernando and Suzana -, looking to highlight the points of intersection and pointing elements of complementarity between them.

Keywords: Identity; Migration; Memory; Dictatorship. 


\section{Introdução}

onchas azuis como corvos descansam ao sol, depositadas pelo mar na areia das praias cariocas, enquanto corvos azuis como as conchas das praias cariocas sobrevoam a paisagem árida de Denver, Colorado. Corvos metafóricos pairam nas memórias daqueles que viveram as agruras da ditadura militar brasileira, procurando por despojos dos quais se alimentar. Essas são algumas das possíveis chaves para a leitura de Azul corvo, romance publicado pela primeira vez em 2010, o quinto de Adriana Lisboa, escritora carioca que hoje vive em Austin, no estado do Texas, Estados Unidos, cujos livros, internacionalmente premiados, já foram traduzidos para mais de vinte idiomas.

A narradora-protagonista de Azul corvo chama-se Evangelina, Vanja. Sem ter conhecido o pai, que não chegou a saber de sua existência, visto que ele e a mãe da personagem afastaram-se após um breve relacionamento, Vanja se vê órfã aos treze anos, em decorrência da morte da mãe, Suzana, acometida por um câncer.

Frente a essa nova vida, na qual tudo havia mudado, em uma tentativa de não sucumbir à metamorfose negativa que sente começar a desenvolver-se dentro de si, Vanja troca a imensidão do mar de Copacabana pela imensidão semiárida de Lakewood, subúrbio de Denver, Colorado, onde inicia uma busca por seu pai biológico, Daniel. Em Lakewood, Vanja é recebida por Fernando, homem com o qual Suzana foi casada ao longo de seis anos, em um período anterior ao seu nascimento, e quem, por motivos apenas especulados no decorrer da narrativa, acata um pedido de Suzana dando seu sobrenome à bebê recém-nascida e afastando-se delas em seguida, até ser contatado pela menina, treze anos depois, com a notícia do falecimento da antiga esposa e com um pedido de ajuda.
A busca de Vanja pelo pai é uma busca por identidade, por pertencimento. A perda materna representa a perda dos laços identitários e afetivos dessa personagem. A mãe sempre lhe bastou. Faltando a referência materna, ela conta com o suporte de Fernando, nos Estados Unidos, e de Eliza, sua tia, irmã de criação de Suzana, no Brasil, ambas pessoas com as quais ela não possuía vínculos significativos, como pontuado por ela mesma ao refletir, logo após viajar aos Estados Unidos, o quanto era "curioso como as pessoas centrais da minha vida agora eram todas periféricas. A tia de criação. 0 ex-marido da minha mãe" (LISBOA, 2014, p. 58). A passagem do tempo e as mudanças por ele operadas nas personagens modificam essas relações. Assim, embora encontrar o pai biológico seja seu principal objetivo aos treze anos, quando, aos vinte e dois, a narradora recorda as ações que empreendeu para atingi-lo, fica claro que esse objetivo diminui sua importância frente a tudo o que ela vivenciou e frente aos laços que criou.

\section{Fernando, Suzana, Vanja: três histórias cruzadas}

"E tudo se orientava pela sombra potencial do passado - uma sombra de meio-dia, que você não vê, mas sabe se guardar em segredo nas coisas, pronta para começar a vazar pelo chão assim que o planeta virar um pouquinho de perfil" (LISBOA, 2014, p.27). É dessa forma que Vanja se refere aos seus últimos momentos em solo brasileiro e começa a relatar seus primeiros dias nos Estados Unidos. Ao mesmo tempo em que narra a sua vida em Lakewood e as etapas do processo que empreendeu até conhecer Daniel, o pai biológico, Vanja escreve a trajetória de vida de Suzana e de Fernando, cujas histórias e identidades influenciam diretamente na história e na identidade da personagem.

Evangelina sintetiza a figura materna ao dizer: “[...] minha mãe não era de caminhar por cima dos próprios passos. Quando ia embora, ia embora. 
Quando abandonava, abandonava" (LISBOA, 2014, p. 42). Embora Suzana não revisitasse seu passado, Vanja é impelida a caminhar por cima dos passos da mãe, fazendo do destino daquela o seu ponto de partida.

A vida de Suzana chegou ao fim aos quarenta e dois anos e sua parada final foi a cidade do Rio de Janeiro. Tendo ela própria ficado órfã de mãe aos nove anos, emigrou com o pai, um geólogo que trabalhava para uma empresa petroleira, para os Estados Unidos, enquanto Elisa, a irmã de criação, ficou no Rio de Janeiro. Em determinado momento de sua adolescência e por motivos não explicitados no texto, Suzana e o pai cortaram laços e ela mudou-se para Albuquerque, no Novo México, inaugurando ali, conforme a narradora, seu costume de "romper relações com os homens e desaparecer de suas vidas" (LISBOA, 2014, p.66).

A narrativa aponta para dois homens, em especial, com os quais o costume iniciado com o avô da narradora foi perpetrado: Fernando e Daniel. Suzana e Fernando foram casados por seis anos, entre o final da década de setenta e o início da década de oitenta. Mesmo depois de quatro anos separados e sem contato, a pedido de Suzana, Fernando registrou Evangelina como sua filha e os laços entre eles foram cortados novamente. Já Daniel, o pai biológico, não chegou a ser informado sobre a gravidez da mulher com a qual teve um breve relacionamento.

Em 1990, Suzana voltou para o Brasil para viver no Rio de Janeiro como professora de Inglês e Espanhol, ofício que já praticava informalmente nos Estados Unidos, onde também ensinava Português. A aprendizagem daqueles dois idiomas é o maior dos legados que ela deixa para a filha, pois dominá-los aos treze anos permite que ela viaje e instale-se no exterior. 0 texto dá destaque à questão da língua em diversos trechos. O domínio do idioma local é apontado como fator preponderante para a sobrevivência e integração, ao mesmo tempo em que o sotaque que Vanja carregava, imperceptível para ela, mas perceptível para aqueles que têm a língua inglesa por idioma materno, marcava sua estrangeiridade:

Foi ela quem me ensinou inglês e espanhol. Era o que ela sabia fazer. Se fosse professora de ioga, teria passado doze anos me ensinando ioga, e se trabalhasse na lavoura eu teria uma enxada antes mesmo de aprender a falar. Era o que ela sabia fazer e achava um desperdício não deixar para mim, de graça, como herança de vida, qualquer conhecimento que fosse. (LISBOA, 2014, p. 35)

Os ensinamentos maternos, porém, vão além da língua. A narradora carrega da mãe o senso prático e direto, características de Suzana que acompanham Vanja durante todo o tempo compreendido pela narrativa. Ela foi criada para ser prática, forte, com liberdade para fazer perguntas e responsabilidade para lidar com a sinceridade das respostas. É a força demonstrada pela narradora em tomar as rédeas da própria vida, inclusive, que impede o texto, em várias passagens, de tornar-se dramático ou melancólico. Nenhum desses adjetivos, porém, a preparou para o choque de saber que não restava muito tempo compartilhado entre a mãe e ela. Nesse sentido, é interessante notar que, quando Suzana conta para Vanja sobre sua doença, a narradora não reproduz o diálogo que elas tiveram tal qual ele aconteceu, apesar de ter as informações necessárias, já que foi uma das personagens principais daquele momento. Ela, que até então conta sua história utilizando a primeira pessoa do singular, cria um narrador de terceira pessoa, assumindo o lugar de espectadora, não mais de protagonista:

A coisa importante que ela precisa contar à filha é a única inteiramente previsível, só que vai acontecer um pouco antes da hora. Ela explica, fala, depois ouve. Responde a todas as perguntas. As perguntas não acabam até que acabam. E com ela a tarde cartão postal e a necessidade de respostas. (LISBOA, 2014, p.71-72).

Até o momento em que Suzana falou para Vanja sobre sua doença, a menina nunca se preocupou em saber sobre seu pai. Quando Fernando 
pergunta-lhe por que ela nunca questionou Suzana sobre o paradeiro paterno, Vanja responde que foi "porque eu não precisava saber. Porque acho que ela não sabia. Porque acho que ela não ia querer me dizer. Não sei" (LISBOA, 2014, p.131). A mãe, que abandonava os homens e não voltava sobre os próprios passos lhe bastava. Assim, com a passagem de Suzana, Vanja se encontra em uma "guerrilha interna" (LISBOA, 2014, p. 74) entre seus próprios sentimentos e a imagem que os outros tinham da menina órfã, que a fazem emigrar para não sucumbir. São os ensinamentos que Suzana transmitiu à filha que a ajudam a dar cabo ao plano de ir em busca do pai biológico.

Se para compor a história da mãe Vanja se vale de suas próprias memórias e das lembranças de Fernando, para compor a história dele, conta com os relatos que ele lhe confia com o transcorrer dos anos e com os documentos que ele guarda em uma velha caixa de vinho. Considerando que a memória está intrinsecamente relacionada com o esquecimento, seja ele proposital ou não, é de se esperar que esses relatos estejam repletos de silêncios, os quais a narradora se ocupa em preencher. Ela é a responsável por contar a história de Fernando e preencher as lacunas que o trauma que ele viveu no início da vida adulta não o deixa completar:

Olho para os meus braços sem cicatrizes e penso cortes, e penso choques elétricos. E me pergunto como as vidas viradas ao avesso e as pessoas viradas ao avesso reencontram o seu direito.

Não reencontram (LISBOA, 2014, p. 156).

Se as vidas viradas ao avesso não reencontram seu lado direito, é de se pensar que, ou elas se adaptam, ou se resignam. Fernando se resignou. "O homem que se acostumava”. Não fosse essa indicação dada pela narradora, seria difícil imaginar que o homem de cinquenta e poucos anos que a recebeu em sua casa, em Lakewood, era o mesmo homem que esteve na
Academia Militar de Pequim e um dos homens mais destros a participar da guerrilha armada na região do Araguaia entre o final dos anos sessenta e o início da década de 1970.

A Guerrilha do Araguaia foi uma das ações de luta armada que se desenvolveram durante o regime ditatorial brasileiro (1964-1985). Teve início em 1966, quando líderes e militantes do Partido Comunista do Brasil se dirigiram às proximidades dos rios Araguaia e Tocantins, em uma região de tríplice fronteira que hoje compreende o sudeste do estado do Pará e o norte do Tocantins, além do Maranhão. Descrentes de que transformações sociais ocorreriam efetivamente através de reformas políticas, os cerca de 100 integrantes da guerrilha acreditavam que a revolução deveria ser iniciada no campo, pelos camponeses, aquela que consideravam a classe revolucionária por excelência ${ }^{1}$.

Através de ações de integrantes do Departamento de Inteligência e Repressão do Exército infiltrados nas comunidades e do trabalho conjunto das Forças Armadas que, entre 1972 e 1974, deslocaram para a região cerca de 4000 homens (SCHWARCZ, 2015, p. 462), a guerrilha foi desarticulada e a maioria de seus integrantes assassinados até 1974, através da Operação Marajoara.

Da vida de Fernando nos Estados Unidos, a narradora pouco conta ao leitor, talvez porque pouco saiba. Ele parece se encaixar no que Walter Benjamin (1994) chama de um ser "pobre em experiência comunicável", ou seja, apesar de ter experiências para comunicar, Fernando perde a capacidade de intercambiá-las pela transformação desmoralizante pela qual passou durante seu período de militância.

${ }^{1}$ Informações sobre a história, organização e motivações dos grupos de luta armada, como o exposto neste trabaho, podem ser encontrados no site memoriasdaditadura derger, iniativa do Instituto neste trabalho, podem ser encontrados no site memoriasdaditadura.org.br, iniciativa do Instituto Vladimir Herzog, em resposta à demanda da Secretaria de Direitos Humanos da Presidência da República pela criação de um portal para a divulgação da História do Brasil durante os anos de 1964 a
1985 junto ao grande público. 
Garçom em um pub londrino, ele conheceu e se apaixonou por Suzana e, por causa dela, emigrou para o Colorado. Depois de seis anos vivendo casados, no Novo México, e de quatro anos sem verem-se, Fernando atende a um chamado da ex-mulher e registra como sua filha a bebê que ela acabara de dar à luz, reestabelecendo, em seguida, o silêncio e a distância entre os dois, agora três. Quando Vanja e Fernando se reencontram, treze anos depois, ele continua solteiro, sem filhos e trabalha como segurança em uma biblioteca pública de Denver, complementando sua renda fazendo faxinas.

Ainda que esteja ambientado e incluso na sociedade norte americana através da língua, do trabalho e da compreensão dos costumes, Fernando é um imigrante, e sua vida no Brasil, seu país de origem, é bastante explorada ao longo da narração de Evangelina, principalmente os anos que se relacionam com sua atuação na Guerrilha do Araguaia, fato importante na construção da narrativa, e os momentos imediatamente posteriores a sua deserção, quando ele buscava fugir encobrindo seus rastros. Neste ponto, mostram-se produtivas as reflexões de Seligmann-Silva (2013), que caracteriza o rastro como um termo-chave da modernidade. 0 estudioso cita Benjamin, para quem deixar rastros é "habitar e viver no mundo moderno burguês" (SELIGMANN-SILVA, 2013, p. 40) ao mesmo tempo em que reflete sobre a necessidade de apagar os rastros para que seja possível sobreviver à determinadas situações da modernidade, como ao poder e à violência exercidos por um Estado totalitário, contexto no qual "o poder torna-se exercício de falsificação. Se o Estado, mesmo nas teorias jusnaturalistas mais conservadoras, deveria preservar a vida, no governo totalitário ele se transforma em negação da vida e em falsificação" (SELIGMANN-SILVA, 2013, p. 42).

Deste modo, da mesma forma que Vanja emigra para os Estados Unidos em busca do pai biológico para não sucumbir à morte da mãe, Fernando emigra para não sucumbir à morte eminente que assalta os guerrilheiros e acaba nos Estados Unidos pelas mãos de Suzana. É a mesma mulher, mãe e ex-esposa, que faz ambos moverem-se, em momentos distintos, para um lugar comum. Além disso, Fernando fez uma promessa para Suzana:

Você promete? perguntou Suzana, antes de pegar no sono.

Prometo o quê? ele quis saber.

Promete primeiro e eu digo depois.

Prometo.

$[\ldots]$

Mas ela não disse. Afundou a cabeça entre dois travesseiros e fabricou uma toca com a coberta e se aninhou no sono, na felicidade do sono, na inconsequência do sono. Como Fernando nunca soube, portanto, o que prometeu, teve que improvisar o cumprimento da promessa (LISBOA 2014, p. 241).

Sem saber o que estava prometendo, ele esperou anos no mesmo lugar, pronto para cumprir o combinado, fosse o que fosse, até que, após registrar Vanja como sua filha, pensar em movimentar-se deixou de ser importante e ele se deixou ficar em Denver. Quando Vanja entra em contato, fiel à promessa, ele não pode negar-se a recebê-la e ajudá-la.

Aluno evadido do curso de geografia da Universidade Federal de Brasília e Militante da Ação Popular, Fernando foi enviado, em 1966, junto com mais catorze militantes, para a Academia Militar de Pequim, para aprender técnicas de guerrilha e luta armada. Depois de três anos, já de volta ao Brasil, passou a atuar no Destacamento A da base da Faveira, sob o pseudônimo de Chico Ferradura. Mateiro habilidoso, Fernando/Chico também foi habilidoso ao prever que a guerrilha estava fadada ao fracasso e, um mês antes de os grupos guerrilheiros serem dizimados pelo Exército Brasileiro, escolhe desertar, fugindo em meio à mata, enquanto estava a caminho, junto com seu grupo, de um ataque: 
Mas houve um momento, antes do raiar do dia, enquanto os comunistas do Araguaia se dirigiam à que seria sua primeira ação militar bem-sucedida, em que Chico parou. Os outros continuaram, imbuídos de seus pés e mãos e olhos e armas, e Chico parou.

Ninguém viu (LISBOA, 2014, p. 246).

Como é possível notar no trecho citado, a narradora de Azul Corvo assume uma posição de narradora heterodiegética quando reconstrói as histórias alheias. Ainda que o relato seja realizado em terceira pessoa, Sarlo (2007, p.14) nos lembra que "as modalidades não acadêmicas de texto [histórico] encaram a investida do passado de modo menos regulado pelo ofício e pelo método, em função de necessidades presentes, intelectuais, afetivas, morais ou políticas". É sempre Vanja, um ser dotado de subjetividades e que carrega uma necessidade, um propósito ao contar, quem narra a vida de Chico, não tendo o leitor, em nenhum momento, acesso à voz dele. Dessa forma, a história de Fernando/Chico não assume um tom confessional ou de ressignificação do passado vivido pela personagem.

É importante lembrar que Fernando conta a sua história para uma criança de treze anos que a reconta aos vinte e dois. Onze anos se passaram entre a experiência da escuta e a narrativa. Temos, assim, uma narradora adulta que recupera memórias de infância e de pré-adolescência e histórias que lhe foram confiadas ao logo desses onze anos. Isso tem algumas implicações, como por exemplo, o fato de que ela percebe a importância ou a curiosidade que orbitam alguns detalhes das histórias de Fernando apenas quando as rememora e já não tem a quem perguntar por esclarecimentos, como é o caso do codinome Chico Ferradura, que Fernando assume durante seu tempo na guerrilha:

Eu nunca soube de onde veio o codinome. Como é que Fernando virava Chico e ainda por cima ganhava uma ferradura. Essa foi uma das coisas que ele não me contou durante o tempo em que moramos juntos, e uma das coisas que não constavam dos papéis que me deixou examinar [...] (LISBOA, 2014, p. 57).
Além disso, as histórias de Fernando são repletas de vazios e silêncios que a narradora se ocupa em completar. "Afinal, se as pessoas não me forneciam detalhes, eu tinha o direito moral de providenciá-los eu mesma" (LISBOA, 2014, p.61). Uma das providências tomadas por ela para preencher as lacunas da narrativa de Fernando foi, claramente, a realização de uma pesquisa histórica. A pesquisa permitiu a ela registrar, através da palavra escrita, as memórias de Fernando de forma satisfatória, enquanto situava-as dentro de um contexto histórico e político. Ao tratar do passado de Fernando como militante político, o romance permite-nos refletir sobre a memória coletiva de nossa nação. Ainda há muito desconhecimento e questões sem resposta sobre os anos de ditadura militar. A narradora deixa claro que a história oficializada pelos discursos institucionais difere da história tal qual vivida por Fernando. Ao falar sobre a história brasileira dos anos 19601980 aprendida na escola, Evangelina afirma que "Era como se Fernando e eu vivêssemos em países distintos" (LISBOA, 2014, p. 68). A afirmação nos remete às reflexões de Jaques LeGoff (1990, p.368) para quem

tornarem-se senhores da memória e do esquecimento é uma das grandes preocupações das classes, dos grupos, dos indivíduos que dominaram e dominam as sociedades históricas. Os esquecimentos e os silêncios da história são reveladores desses mecanismos de manipulação da memória coletiva.

A narradora assume o papel que desempenha como pesquisadora. Além de afirmar que exerce seu direito moral de preencher as lacunas que encontra, Vanja transcreve documentos que existem fora do mundo ficcional de Azul Corvo e que dão conta das operações realizadas pelas Forças Armadas, e trechos de conversas em fóruns, na internet, sobre a atuação dos militares. Além de enriquecer a narrativa, isso confere coerência ao texto. Afinal, há que se considerar, por exemplo, que Fernando não participou do movimento até o fim, ele é um desertor, mas a narração de Vanja relata as 
operações que levaram ao desmantelamento da guerrilha e à execução de seus integrantes, em momentos nos quais ele já estava no exílio.

\section{A condição de Fernando e Vanja nos EUA e a criação de laços}

Vanja constrói a sua narrativa a partir de memórias, suas e alheias, compartilhadas e individuais. São memórias que a mãe e que Fernando compartilharam com ela; memórias sobre a mãe e sobre Fernando que ela criou; são memórias sobre si. Para Le Goff (1990, p.477) "A memória é um elemento essencial do que se costuma chamar identidade, individual ou coletiva, cuja busca é uma das atividades fundamentais dos indivíduos e das sociedades de hoje, na febre e na angústia". A tese do historiador francês corrobora nossa afirmação de que a busca de Vanja pelo pai é, na realidade, uma busca por identidade, por pertencimento. Apesar de encontrar o que foi buscar, Evangelina não encontra na forma nem nas pessoas que esperava.

De acordo com Sarlo (2007, p. 10):

É possível não falar do passado. Uma família, um Estado, um governo, podem sustentar a proibição; mas só de modo aproximativo ou figurado ele é eliminado, a não ser que se eliminem todos os sujeitos que o carregam [...]. Em condições subjetivas e políticas "normais", o passado sempre chega ao presente.

Em Azul Corvo, tanto o passado familiar quanto uma parcela importante do passado recente do Brasil chegam ao presente através do convívio entre Evangelina e Fernando, do desejo de futuro atrelado à curiosidade pelos passados que, de alguma forma, conectam as personagens. Criando essas conexões, Adriana Lisboa se mostrou uma escritora habilidosa na construção de suas personagens e na costura do enredo de seu livro. As trajetórias pessoais e as personalidades de Evangelina e de Fernando são, em muitos momentos, reflexo e complemento uma da outra. As experiências de perda materna e de deserção da atividade guerrilheira frente à morte iminente colocam as duas personagens centrais de Azul Corvo em situações limites, em que se veem desprovidas de laços afetivos e de possibilidades de um futuro satisfatório. Ambas encontram a mesma solução: sair do país. Fernando, para fugir de uma provável execução e dos próprios sentimentos de vergonha e medo; Vanja para encontrar o pai biológico, único laço sanguíneo que lhe restava, e não sucumbir à carga que se lhe impunha frente à orfandade. $\mathrm{O}$ plano de fundo histórico envolvendo a ditadura militar, em específico as ações empreendidas por militantes e por militares naquela que ficou conhecida como a Guerrilha do Araguaia, dão ao livro um tom político sem fazer dele um texto panfletário e sem disputar espaço com a história pessoal da narradora.

Ao refletir sobre a presença da memória nas artes e na política, o crítico alemão Andreas Huyssen (2002) aponta para aquilo que classifica como um dos fenômenos culturais e políticos mais surpreendentes dos últimos anos: a preocupação que as sociedades ocidentais vêm dispensando à memória em contraste com o movimento característico das primeiras décadas do século XX, quando a preocupação central era dispensada ao futuro. Segundo o estudioso, os processos de descolonização e o surgimento de grupos sociais que buscavam historiografias alternativas e revisionistas para seus passados, nos anos 1960, seriam os responsáveis por redirecionar o olhar das produções e começar a lançar o foco sobre a memória. Essa cultura da memória, como Huyssen a denomina, também se faz presente nas sociedades pós-ditatoriais da América Latina, e é a responsável por determinar "con alcance variable el debate cultural y político con respecto a los desaparecidos y a sus hijos [...], poniendo en el tapete cuestiones fundamentales sobre las violaciones de los derechos humanos, la justicia y la responsabilidad colectiva (HUYSSEN, 2002, p. 19). 
No Brasil, desde a redemocratização do país diversas foram as elaborações literárias publicadas que procuraram refletir sobre o golpe de 1964, a ditadura militar e seus desdobramentos, seja utilizando-a como temática central, quando encontramos relatos de engajamento político, resistências, desaparecimentos e torturas, seja como plano de fundo para o desenvolvimento de enredos. Azul corvo, ao tratar da Guerrilha do Araguaia e ao retratar as experiências de Fernando no exílio, pode ser incluído nesse cenário.

Quanto à escolha por abordar essa temática, em entrevista à revista IstoÉ Gente Lisboa deixa claro que ela não foi um elemento prioritário, mas uma ferramenta que lhe permitiu desenvolver a história principal:

Era um assunto que me instigava desde adolescente, justamente por ser um tema evitado. Na escola, a Guerrilha no Araguaia era tratada en passant. Quando pensei no Fernando como exilado, como alguém que saiu do Brasil tão desgostoso a ponto de nunca mais voltar, a ditadura foi a primeira coisa que me veio à cabeça, e o fato de ser um ex-guerrilheiro me pareceu inédito (LISBOA, 2010, n.p.).

A migração e o estrangeiro são os pontos que primeiro saltam aos olhos do leitor de Azul Corvo, da epígrafe que abre o romance às páginas que, em um estilo de prosa poética, se ocupam do clima e do espaço geográfico. Fernando é um homem expatriado que saiu do Brasil nos anos 70 fugindo da repressão militar e que decidiu permanecer vivendo no exterior mesmo após a anistia. Enquanto Vanja trocou a imensidão marítima de Copacabana pela imensidão desértica do Colorado, Fernando escolheu deixar-se viver nesta imensidão desértica, em uma comparação ou em negação direta com a vastidão amazônica de sua experiência traumática; o estranhamento que ele sente ao chegar à floresta que será sua casa nos próximos meses também é sentido por Vanja ao chegar em Denver, assim como ambos sentem as mudanças, frutos dos distintos ambientes, sobre seus corpos e mentes.
Evangelina, por sua vez, não é uma imigrante convencional. Ela nasceu nos Estados Unidos, mas deixa claro que, ao voltar para lá aos treze anos, sentiu-se uma estrangeira em sua terra natal. Dessa forma, pode-se afirmar que Azul Corvo, ao utilizar o deslocamento geográfico das personagens como um dos motivadores de sua trama, lida com a questão do pertencimento, tanto em um nível coletivo quanto individual, sendo este último aquele para o qual temos voltado nosso interesse neste trabalho.

No início da narrativa, a personagem não pertence àquele território. Mais do que desconhecido, ela não o relaciona a nenhuma vivência significativa. Pode-se pensar, assim, que Denver assume um papel de entre-lugar. "Lakewood, Colorado. Um lugar estranho. Mas eu não me incomodava com a sua estranheza, porque aquele subúrbio de Denver era, para mim, um mero utilitário" (LISBOA, 2010, p. 18).

Além de sentir-se estrangeira por questões territoriais e culturais, Vanja sentia-se estrangeira de si mesma:

Ter treze anos é como estar no meio de lugar nenhum. 0 que se acentuava devido ao fato de eu estar no meio de lugar nenhum. Numa casa que não era minha, numa cidade que não era minha, num país que não era meu, com uma família de um homem só que não era, apesar das interseções e das intenções (todas elas muito boas), minha (LISBOA, 2014, p. 16).

A mudança começa a ocorrer quando ela passa a se ver inclusa em um grupo social, em uma situação compartilhada. Um dos exemplos mais marcantes é a cena na qual, junto com outras crianças, Fernando empurra Vanja e Carlos, seu amigo salvadorenho, pelas encostas cobertas de neve, o que faz a narradora exaltar que "[...] agora eu era um deles, sim, análoga, comparável, semelhante. [...] Eu também gritava, eu também levava tombos, eu também" (LISBOA, 2014, p. 187).

Nesse processo, também muda a forma como Evangelina encara o espaço e o ambiente ao seu redor. Ela afirma que, aos poucos, a casa de 
Fernando foi se tornando a sua casa, assim como os invernos e os verões do Colorado, tão diferentes quando comparados aos cariocas, os seus invernos e os seus verões. A narradora, porém, não deixa de considerar-se brasileira ou passa a considerar-se norte-americana. A conclusão de Vanja é diferente. "Num belo dia eu me dei conta de que não tinha importância o país onde eu estava. A cidade onde eu estava. Outras coisas tinham importância. Não essas" (LISBOA, 2014, p. 293).

Por "outras coisas", apontamos os laços que Vanja cria com Fernando:

Você é o que meu? Porque pela minha certidão de nascimento você é meu pai, mas não é meu pai de verdade, então é o quê?

[...]

Não sei, o que você quiser que eu seja, ele respondeu. (LISBOA, 2014, p.200)

Apesar de ter encontrado Daniel, seu pai biológico, Vanja não encontrou nele o pai pelo qual procurava, nem as memórias maternas pelas quais buscava. Isso ela encontrou em Fernando a quem, pela afetividade desenvolvida, passou a considerar seu pai. Quando se muda do Brasil para os Estados Unidos, Vanja leva a mãe consigo, na aparência e nos ensinamentos que ela lhe transmitiu. Ao final da narrativa, além de identificar-se com o clima do Colorado e com a casa de Fernando, Vanja trabalha como bibliotecária na mesma biblioteca em que ele trabalhou como segurança, dirige um carro da mesma marca que Fernando dirigia e perpetua com Carlos, o amigo também estrangeiro, os costumes que desenvolveu ao lado do ex-marido da mãe.

\section{Conclusão}

Dentre a série de lugares descritos, movimentações geográficas realizadas e personagens de diferentes nacionalidades presentes em Azul
Corvo, este trabalho procurou dar destaque ao encontro das histórias de vida de Evangelina, jovem narradora-personagem do romance, e Fernando, seu pai adotivo. Para além do encontro físico, que ocorre quando Evangelina migra à procura de Fernando, após o falecimento de sua mãe, para que ele lhe auxilie a encontrar seu pai biológico, as histórias dessas duas personagens complementam-se. Quase vinte anos antes desse encontro, Fernando havia feito uma promessa a Suzana. Essa promessa, em sua inquisição silenciosa, abarcava tudo e qualquer coisa que viesse da mulher que o deixou, desde registrar a filha que não era sua, até recebê-la em casa, anos depois, e ajudá-la a encontrar seus familiares biológicos. Fernando fez mais do que o prometido, ele tornou-se não a figura paterna que Vanja viajou à procura, mas aquela que ela desejou que tivesse ficado ao lado de sua mãe e construído com elas uma família longeva, o que pode ser justificado através dos últimos parágrafos do texto, nos quais Vanja narra como teria sido a sua vida se ela tivesse o poder de conduzir as coisas de modo diferente daquele como tudo aconteceu.

Considerando que a busca de Vanja é, em síntese, uma busca pelos laços identitários e afetivos que se perdem com a morte de sua mãe, a história de Fernando complementa a de Evangelina não só por ele abraçá-la como filha, mas também por ser quem pode transmitir-lhe memórias da mãe de um tempo em que a narradora ainda nem havia nascido. $O$ vínculo que Vanja cria com Fernando expande-se para a casa e o estado onde vivem, pois, com o passar do tempo, esses espaços transformam-se em cenários de experiências significativas, sentimentais, como as brincadeiras na neve nos invernos, a caminhada pelo labirinto no milharal durante o halloween, as descidas pelo rio em câmeras de pneu e os mergulhos na piscina pública nos verões. É nesse sentido que, ao afirmar que que outras coisas que não o país ou a cidade no qual se encontrava tinham importância, Vanja modifica a visão de lar que possuía no início da narrativa e junto com ela a visão de 
família, de núcleo identitário, ligado menos a relações genealógicas e mais a relações afetivas.

\section{Referências}

BENJAMIN, Walter. Magia e técnica, arte e política: ensaios sobre literatura e história da cultura. São Paulo: Brasiliense, 1994.

HUYSSEN, Andreas. En busca del futuro perdido: cultura y memoria en tiempos de globalización. México: Fondo de Cultura Económica, Goethe Institut, 2002.

LE GOFF, Jaques. História e memória. Campinas, SP: Editora da UNICAMP, 1990.

LISBOA, Adriana. Azul Corvo. Rio de Janeiro: Objetiva, 2014.

LISBOA, Adriana. Em seu quinto romance, Azul-Corvo, escritora narra a improvável amizade entre uma adolescente órfã e um ex-guerrilheiro. Revista IstoÉ Gente, n. 580, out. 2010. Entrevista concedida a Suzana Uchoa Itiberê. Disponível em: <https: //www. terra.com.br/istoegente/edicoes/580/artigo189292-1.htm>. Acesso em: 03 mar. 2018.

PEIXOTO, Rodrigo Corrêa Diniz. Memória social da Guerrilha do Araguaia e da guerra que veio depois. Boletim do Museu Paraense Emílio Goeldi. Ciências Humanas, Belém, v. 6, n. 3, p.479-499, set./dez. 2011.

SARLO, Beatriz. Cultura da memória e guinada subjetiva. São Paulo: Companhia das Letras; Belo Horizonte: UFMG 2007.

SCHWARCZ, Lilia M; STARLING, Heloisa M. Brasil: uma biografia. São Paulo: Companhia das Letras, 2015.

SELIGMANN-SILVA, Marcio. Ficção e imagem, verdade e história: sobre a poética dos rastros. Dimensões, Espírito Santo, v. 30, p. 17-51, 2013.

MEMÓRIAS DA DITADURA. Disponível em: <http://memoriasdaditadura.org.br/gruposda-luta-armada/index.html>. Acesso em: 03 mar. 2018.

Recebido em 29/06/2018

Aceito em 11/09/2019. 